\title{
To compare the effect of stretching and core strengthening exercises on Primary Dysmenohrrea in Young females.
}

\author{
${ }^{1}$ Sandeep Kaur, ${ }^{2}$ Prabhnoor kaur, ${ }^{3}$ Sarvanan Shanmugam, ${ }^{4}$ Manpreet Kaur Kang \\ ${ }^{1,2,3,4}$ Department of physiotherapy, Lovely Professional University, India
}

\begin{abstract}
:
Background: Primary dysmenorrhea is defined as difficulty in menstrual flow in the absence of any pelvic pathology. It is the most common gynaecological problem among adolescent females. Incidence of primary dysmenorrhea was reported to be between $50 \%$ and $90 \%$ in different societies. Several studies have shown that the reduction of dysmenorrhea in women, who regularly exercise may be due to effects of hormonal changes on uterine epithelial tissues or an increase in endorphin levels. It appears that exercise has analgesic effects that act in a non-specific way.

Study aim: To compare the effect of stretching and core strengthening exercises on primary dysmenorrhea. Material and Methods: The present experimental study included 105 girls of age 19-25 years with primary dysmenorrhea were selected from lovely professional university and government college, Phagwara.The students were non Athlete and Volunteered for the study, the participants were randomly divided into 3 groups, 2 Experimental gp $\left(1^{\text {st }}\right.$ exp gp $n=35,2^{\text {nd }}$ exp gp,n=35) and control gp $(n=35)$. In the Intervention group the subjects were requested to complete active stretching and core strengthening protocol for 8 weeks (4 days per week, 2 times a day, $10 \mathrm{~min}$ ) at home. In the Pre-test \& post test all the subjects were examined for pain intensity (NPRS), pain duration and use of sedatives tablets during menstruation cycle and side bridge test.

Results: Pain intensity is decreased significantly in both experimental groups that is in Gp1 (p=.0001) and Gp2 $(p=.0001)$ with NPRS and PDQ in Gp 1(p=.0001) and in Gp2 (p=.0001) after post readings of 4 weeks $(p 1)$ and of 8 weeks ( $p 2)$ but the results of control group is non significant

Conclusion: The present result suggested that active stretching and core strengthening both can be safely used as an alternative therapy for pain relief in dysmenorrhoea and this action is not mediated through progesterone. Because we are dealing with a functional problem that is not a disease state, so can truly focus on a holistic approach.
\end{abstract}

Keywords: Primary Dysmenorrhea, active stretching, core strengthening

\section{Introduction}

Dysmenorrhrea, or painful menstruation is one of the most important causes of school absenteeism amongst adolescent girls, because it affects their academic performance, school and sports activities. Dysmenorrhoea is the most common gynaecologic disorder among female adolescents, with a prevalence of $60 \%$ to $93 \%$. Affected women experience sharp, intermittent spasm of pain usually concentrated in the supra pubic area. Pain may radiate to the back of the legs or the lower back. Systemic symptoms of nausea, vomiting, diarrhoea, fatigue, mild fever and headache or light headedness are fairly common. Pain usually develops within hours of the start of the menstruation and peaks as the flow becomes heaviest during the first day or two of the cycle. . The most common effect of menstrual problems on daily routine, reported by unmarried undergraduate medical students was in the form of prolonged resting hours followed by inability to study. Physical activity is also an important behavioural cofactor, people who describe themselves as active have lower levels of inflammatory biomarkers than their sedentary counterparts

Dysmenohrrea is most commonly relieved by medication ranging from commercially available formulas to oral contraceptives. The side effects from such medications are well known (nausea, breast tenderness, and intermenstrual bleeding, dizziness, drowsiness, hearing and visual disturbances).Nonpharmacological treatments for primary dysmenohrrea include bed rest, exercise, application of heat packs, and alternative treatments like Yoga, Aerobics, TENS, MWD, SWD, Pilates, Connective tissue massage, Acupressure.

It was be believed that contracted ligamentous bands in the abdominal region were the causative factor for physical compression of nerve pathways and their irritation, So the stretching exercise was considered very effective. Active stretching exercise will increase the blood flow and metabolism of the uterus during exercise may be effective in the reduction of dysmenorrhoeal symptoms .In another words, improved metabolism is a factor in the reduction of symptoms it is also suggested that increased menstrual pain by uterine muscle contraction is derived from a nervous system that is innervated by the sympathetic nerve hence stress through hyperactivity of sympathetic nerve system via the increase contractibility of uterine muscles lead to 
menstruation symptoms .Consequently, it might be possible to reduce dysmenorrhoeal symptoms by decreased sympathetic over activity through active stretching .

It was be believed that the purpose of core strengthening is to combine the concepts of lumber stabilization and how instability can lead to injury and pain specifically during stressful times of the female body and one of these repetitive stressful times is dysmenohrrea. The lumber portion of spine is sturdy and designed to take the force of the body and it also involved in the origin and insertion of certain musculature and nerve innervations to their correlated areas. If at any time a certain part of the lumbar spine is weak, it is not as its optimal level to handle functional stress, which can result in pain throughout the abdomen, low back, or thighs. These areas just happen to be the same areas that are affected by females suffering from dysmenohrrea. Core strengthening allows the small intrinsic musculature surrounding the lumbar spine to be conditioned for greater performance, this type of training allows for isolation and strengthening of core muscle groups. When these muscles are strong, they are much more prepared to handle daily forces of normal biomechanics, even when the body is under the stress of the menstrual cycle. Core strengthening is a description of the muscular control around the lumbar spine to maintain functional stability. It has been promoted as a preventive regimen, as a form of rehabilitation, and as a performance enhancing program for various lumbar spine and musculoskeletal involvements. Over time it because clear that stability is a process that includes both static positions and controlled movement .This includes both an alignment in sustained postures, as well as movement patterns which reduce tissue strain, avoid causing trauma to the joints or soft tissue, and allow for efficient muscle action.

It is not proven that which exercise is better by supporting articles, so there is need to conduct a study which compares the 2 types of exercises to determine that which group is better, active stretching or core strengthening .Hence we are assuming hypothesis that which exercise will have more better results.

\section{Material And Methodology}

Study design was Experimental design and sample criteria was random sampling and study setting was that data has been collected from the students of Lovely professional university and Ramgarhia college phagwara .Population sample were taken with 105 total subjects,in which $n=35$ in each group. 19-25 years normal young females with Primary Dysmenohrrea and Non Athletic were included in the study and female with History of any specific disease and Compulsory use of specific drugs and having symptoms such as tingling sensation \& abnormal vaginal bleeding and Irregular menstrual cycles \& any history of regular exercises 3days/week [daily average 30-45 min] were excluded from the study.

\section{Procedure}

With the aim to find the effect of stretching and core strengthening exercise on primary dysmenohrrea, 105 subjects were taken randomly and, requested to kindly co-operate during research procedure ,all participants were given information in written and verbally about the objectives and methods of implication ,students who agreed to take part in this study were asked to complete a self administered questionnaire. Student participation was voluntary after filling the written consent form ,the subjects completed a demographic questionnaire that addressed : age at first menstruation, amount of analgesic consumption during menstruation ,pain intensity assessment by NPRS during period and a consent form ,the subjects were given 2 pretest questionnaires after first and second menstrual cycle, dysmenorrhea Questionnaire was filled and side bridge testing was done for all the 3 groups in which pre -readings and post readings (at $4^{\text {th }}$ week and $8^{\text {th }}$ week) were taken.

GROUP A: Experimental group [ $\mathrm{N}=35$ ] was given a questionnaire prior to the stretching exercises, which included 6 stretching exercises in the abdominal, pelvic, and groin regions the subjects were requested to perform the active stretching for 8 weeks (4 days per week twice for $10 \mathrm{~min}$.) furthermore, they were asked to avoid performing stretching exercise during the menstrual cycle. The prescribed exercises were as follows:

1. In the first stretching exercise, the subject were asked to stand, and bend your trunk forward from the hip joint so that the shoulders and back were positioned on a straight line and the upper body was placed parallel to the floor ,duration of holding time was $5 \mathrm{sec}$, repetitions was 10 times.

2. In the second stretching exercise, the subjects were requested to stand then raise 1 heel off the floor, then repeat the exercise with the other heel alternatively. The exercise was performed 20 times

3. In the third exercise the subject were asked to spread their feet shoulder width, place trunk and hands in forward stretching mode, then completely bend her knees and maintain a squatting position, duration of this position was $5 \mathrm{sec}$, the subject then raised her body and repeated the same movement 10 times.

4. In the fourth exercise, the subjects were asked to spread her feet wider than shoulder width. Then the subject was asked to bend and touch left ankle with her right hand while putting her left hand in a stretched position above her head so that the head was in the middle and her head was turned and looked for her left hand, 
this exercise was repeated for the opposite foot with the same method. The exercises was repeated alternatively 10 times for each side of the body

5. In the fifth exercise, the subjects were asked to lie down in the supine position so that the shoulder, back and feet were kept on the floor. In this position the knees was bent with the help of her hands and reached to her chin, the repetition frequency was 10 times

6. In the sixth and last exercise, the subject were asked to stand against a wall and put her hands behind her head and elbows pointed forward in the direction of the eyes, then without bending the verbal column ,the abdominal muscle wall was contracted for $10 \mathrm{sec}$. this exercise was repeated 10 times.

GROUP B : Experimental group $(\mathrm{N}=35)$ was given a questionnaire and then they were asked to perform core strengthening exercises for 4 days per week twice for $20 \mathrm{~min}$ ( 8 weeks) the side bridge test was performed in a side lying position on their dominant side, supported by their elbow ,forearm ,fist and foot of the top leg .the foot of the bottom leg was wrapped around so as to be on top of the other foot,firmly press into the ground with the supporting arm ,and then raise the trunk and pelvis straight upward until they form a straight line with the legs , do not let the trunk rotate forward or back ,nor should the hips move to the rear, hold this position as long as possible while continuing to breathe .The side bridge test was complete when the participants could no longer hold the position correctly, if the subject holds this position for 10-41sec then it is considered Level1, and if holds this position for 41-102 then it is considered Level2, if this position maintain for 103-134 sec then it is considered Level3, if this position hold for $135 \mathrm{sec}$ and greater then it is considered Leve4,from all these levels, a numeric value of subjective complaint was obtained for each subject by having them complete a symptom survey before, at mid point, and after the treatment and this value is predictive criteria for further progression.

The prescribed exercises were as follows

1.Pelvic Bridging :The subject were requested to lie supine and with knee flexed and then raise the pelvis upward till the comfort then hold that position for $5 \mathrm{sec}$ and repetitions was 10 times

2.Plank: The subject were requested to lie prone and then by putting the weight on elbows and toes lift the body upward hold this position for $5 \mathrm{sec}$ and 5 times.

3. Cat and Camel: The subjects were requested to prone kneel and then take a deep breath from nose while making hump in the back (cat) and breathe out from mouth while curving the spine (camel) 10 times.

4.Single leg abdominal press: This exercise is having further 2 phases, The subject were requested for supine lying and then both knees flexed 1(phase1).keep the hand inner side of the knee(applying force outward)and knee is moving inside.2.(phase2)keep the hand outer side of the knee(applying force inward) and knee is moving outside. Repetitions 5 for each side.

5 .Double leg abdominal press: The subjects were requested to lie supine and by bending both knees towards chest and by both hands opposite force (toward the feet) and isometric contraction.10 times.

6.Curl up :The subjects were requested to lie supine and mild knee flexed and clasp both hands behind the head and move the body towards the knee.10 times. After this at $8^{\text {th }}$ week, post reading were taken for NPRS and primary dysmenrrhea questionnaire.

GROUP C: The participants $(\mathrm{N}=35])$ of the control group would not participate in the exercise regimen described. All participants signed a consent form.

The first post reading $(\mathrm{p} 1)$ was taken at $4^{\text {th }}$ week and second post reading (p2) was taken at $8^{\text {th }}$ week.

\section{Procedure in flow chart}

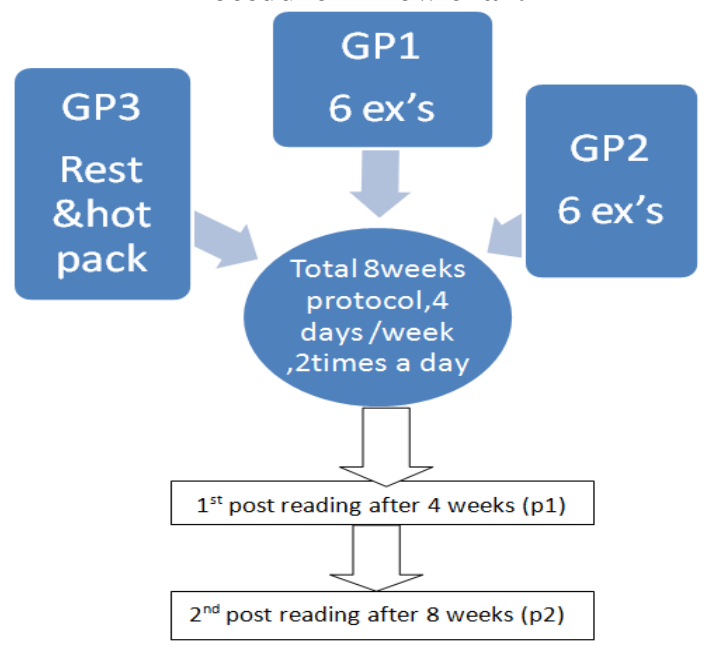




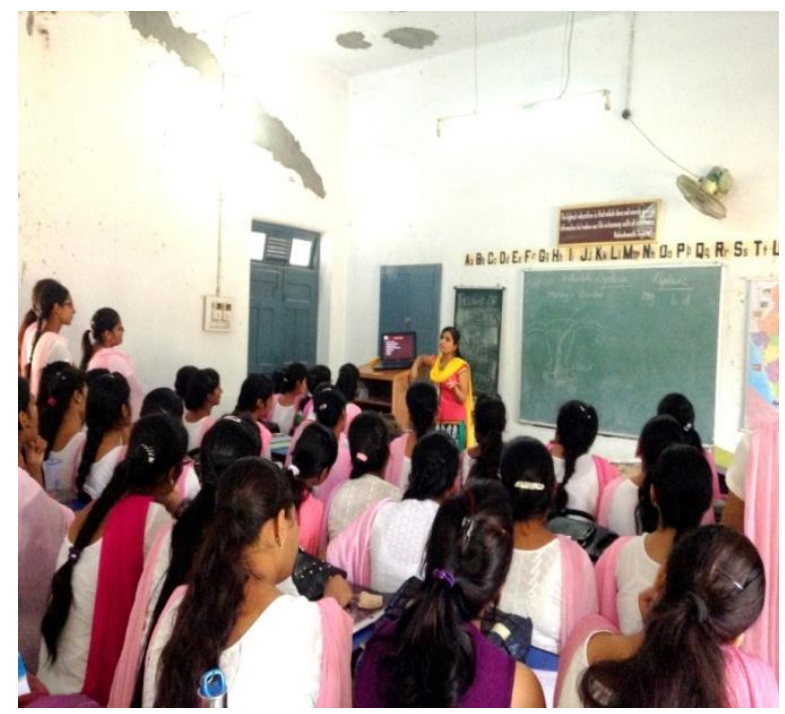

Figure no 1

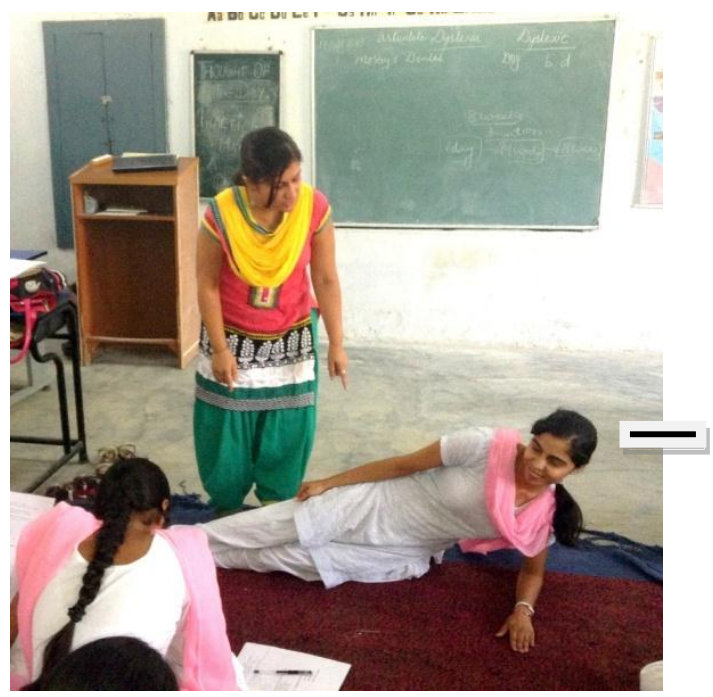

Figure 2

\section{Data Analysis And Results}

Data analysis was carried out after collecting the data for three outcome measures of the subjects in all the three groups consisting of NPRS, Side bridge test, Primary dysmenorrheal questionnaire.

Table 1 Comparison of NPRS scores within the Group A, Group B and Group C

\begin{tabular}{|c|c|c|c|c|}
\hline \multicolumn{2}{|l|}{ NPRS } & $\mathrm{MEAN} \pm \mathrm{SD}$ & F-VALUE & $\begin{array}{ll}\text { LEVEL } & \text { OF } \\
\text { SIGNIFICANCE } & \\
\end{array}$ \\
\hline \multirow[t]{3}{*}{ Group A } & Pre test & $8.91 \pm 0.951$ & \multirow[t]{3}{*}{1617.030} & \multirow[t]{3}{*}{0.0001} \\
\hline & P1 & $3.89 \pm 0.530$ & & \\
\hline & $\mathrm{P} 2$ & $0.83 \pm 0.382$ & & \\
\hline \multirow[t]{3}{*}{ Group B } & Pre test & $9.09 \pm 0.562$ & \multirow[t]{3}{*}{2909.680} & \multirow[t]{3}{*}{0.0001} \\
\hline & P1 & $4.00 \pm 0.243$ & & \\
\hline & $\mathrm{P} 2$ & $0.97 \pm 0.514$ & & \\
\hline \multirow[t]{3}{*}{ Group C } & Pre test & $9.11 \pm 0.832$ & \multirow[t]{3}{*}{251.710} & \multirow[t]{3}{*}{0.0001} \\
\hline & $\mathrm{P} 1$ & $7.74 \pm 0.701$ & & \\
\hline & $\mathrm{P} 2$ & $6.49 \pm 0.742$ & & \\
\hline
\end{tabular}

$\mathrm{SD}=$ standard deviation, $\mathrm{F}$-value $=\mathrm{F}$-test, $\mathrm{S}=$ significant $(\mathrm{P}<0.05)$ 


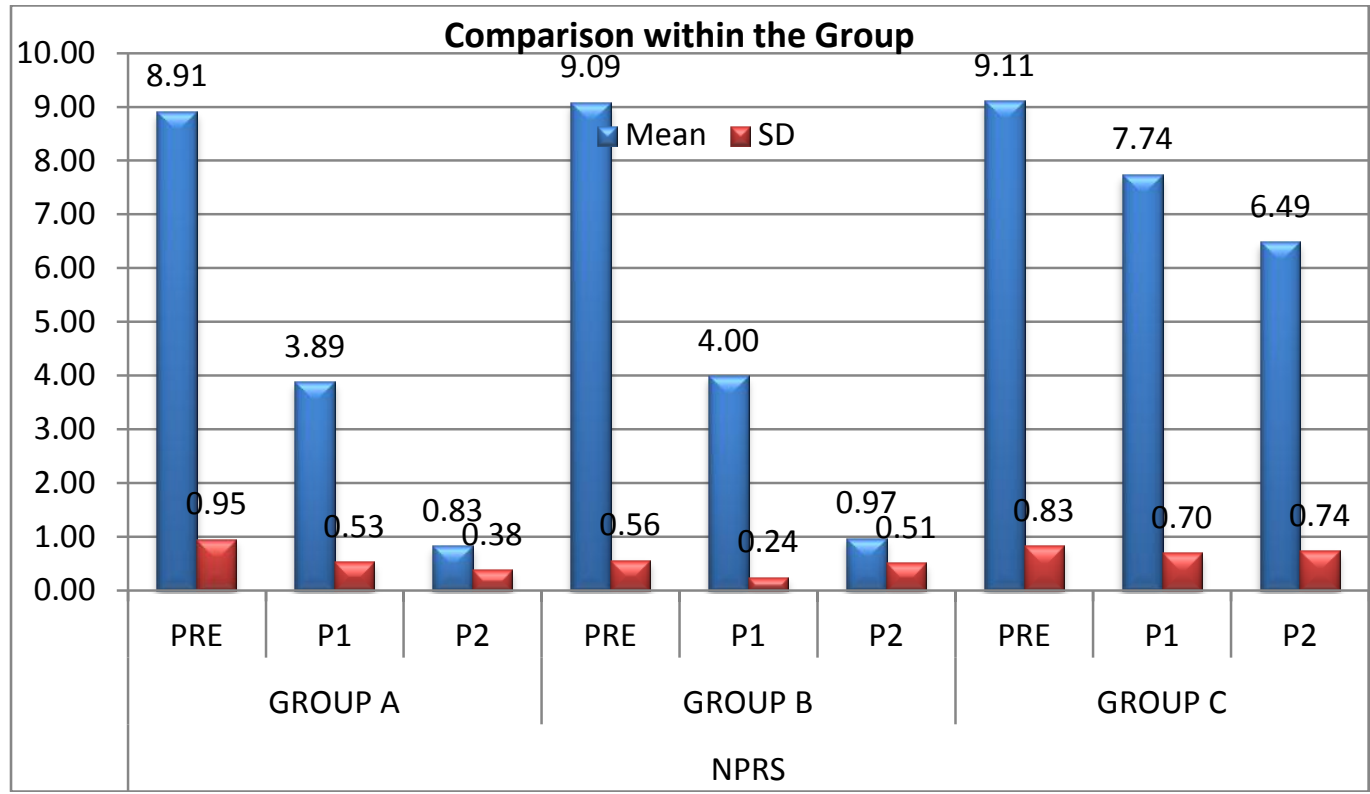

Graph4.2Showing the comparison of NPRS within the GroupA, GroupB \& GroupC (Mean \pm SD)

Table 2 Comparison of PDQ scores within the Group A, Group B and Group C

\begin{tabular}{|c|c|c|c|c|}
\hline \multicolumn{2}{|l|}{ PDQ } & $\mathrm{MEAN} \pm \mathrm{SD}$ & F-VALUE & $\begin{array}{ll}\text { LEVEL } & \text { OF }\end{array}$ \\
\hline \multirow[t]{3}{*}{ Group A } & Pre test & $4.97 \pm 0.169$ & \multirow[t]{3}{*}{539.580} & \multirow[t]{3}{*}{0.0001} \\
\hline & P1 & $3.11 \pm 0.530$ & & \\
\hline & $\mathrm{P} 2$ & $1.66 \pm 0.539$ & & \\
\hline \multirow[t]{3}{*}{ Group B } & Pre test & $4.97 \pm 0.169$ & \multirow[t]{3}{*}{587.910} & \multirow[t]{3}{*}{0.0001} \\
\hline & $\mathrm{P} 1$ & $3.09 \pm 0.562$ & & \\
\hline & $\mathrm{P} 2$ & $1.63 \pm 0.547$ & & \\
\hline \multirow[t]{3}{*}{ Group C } & Pre test & $4.94 \pm 0.236$ & \multirow[t]{3}{*}{189.300} & \multirow[t]{3}{*}{0.0001} \\
\hline & $\mathrm{P} 1$ & $3.89 \pm 0.323$ & & \\
\hline & P2 & $3.34 \pm 0.539$ & & \\
\hline
\end{tabular}

$\mathrm{SD}=$ standard deviation, F-value $=$ F-test, $\mathrm{S}=$ significant $(\mathrm{P}<0.05)$

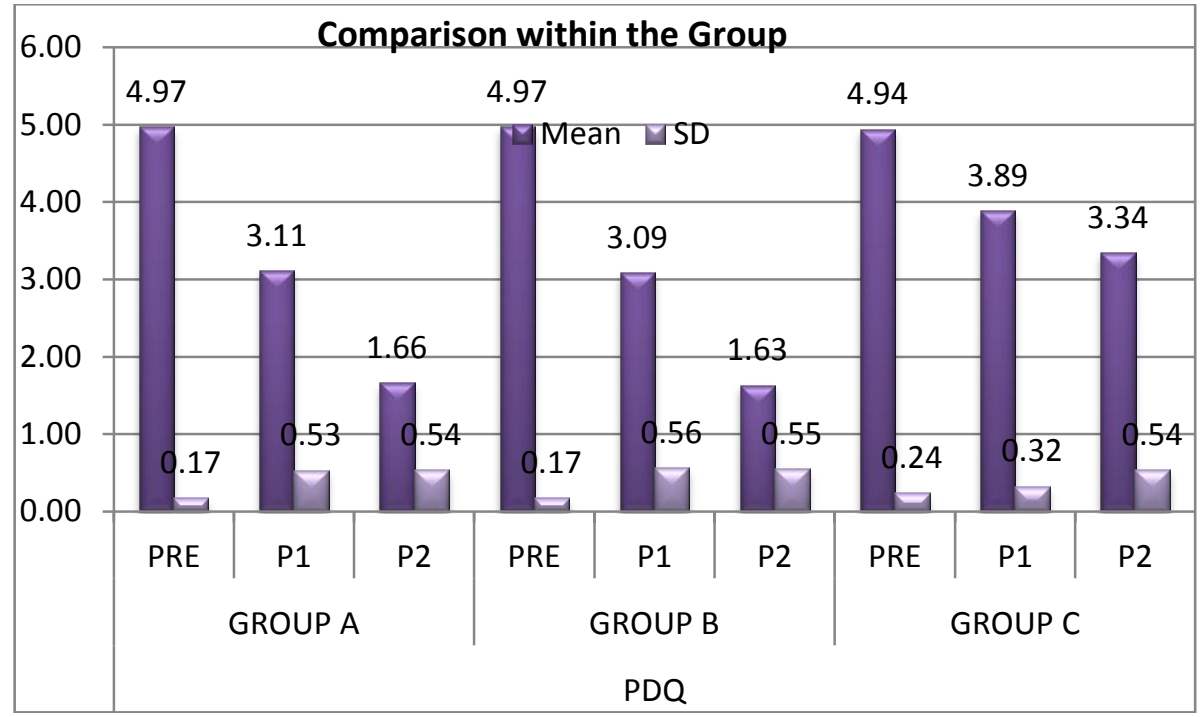

Graph4.3 Showing comparison of PDQ within the Group A, Group B \& Group C (Mean \pm SD) 
Table 3Comparison of Side Bridge Test within the Group A, Group B \&Group C

\begin{tabular}{|c|c|c|c|c|}
\hline \multicolumn{2}{|c|}{ SIDE BRIDGE TEST } & $\mathrm{MEAN} \pm \mathrm{SD}$ & F-VALUE & LEVEL OF SIGNIFICANCE \\
\hline \multirow[t]{3}{*}{ Group A } & Pre test & $10.94 \pm 5.116$ & \multirow[t]{3}{*}{1347.170} & \multirow[t]{3}{*}{0.0001} \\
\hline & P1 & $34.03 \pm 5.096$ & & \\
\hline & $\mathrm{P} 2$ & $56.06 \pm 6.474$ & & \\
\hline \multirow[t]{3}{*}{ Group B } & Pre test & $10.63 \pm 5.515$ & \multirow[t]{3}{*}{1701.090} & \multirow[t]{3}{*}{0.0001} \\
\hline & P1 & $69.69 \pm 9.649$ & & \\
\hline & $\mathrm{P} 2$ & $104.06 \pm 12.609$ & & \\
\hline \multirow[t]{3}{*}{ Group C } & Pre test & $9.71 \pm 4.396$ & \multirow[t]{3}{*}{258.660} & \multirow[t]{3}{*}{0.0001} \\
\hline & $\mathrm{P} 1$ & $19.83 \pm 7.229$ & & \\
\hline & $\mathrm{P} 2$ & $30.17 \pm 9.998$ & & \\
\hline
\end{tabular}

$\mathrm{SD}=$ standard deviation, F-value $=$ F-test, $\mathrm{S}=$ significant $(\mathrm{P}<0.05)$

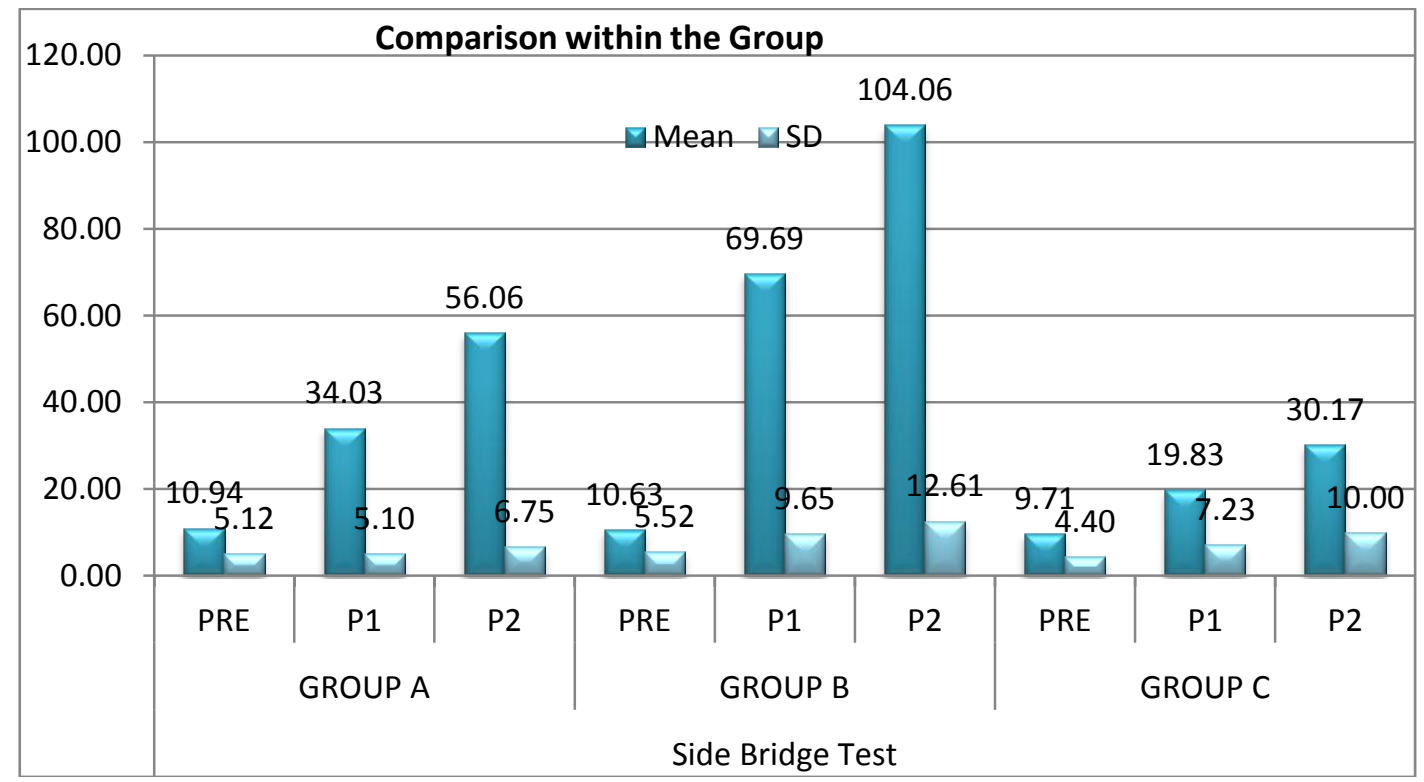

Graph 4.4 Showing comparison of Side Bridge Test within the group A, group B \& group C (Mean \pm SD)

Table 4 Comparison of NPRS scores between the Group A, Group B and Group C

\begin{tabular}{|l|l|l|l|l|}
\hline NPRS & MEAN \pm SD & F-VALUE & LEVEL OF SIGNIFICANCE \\
\hline \multirow{4}{*}{ PRE TEST } & Group A & $8.91 \pm 0.951$ & 0.642 & \multirow{4}{*}{0.531} \\
\cline { 2 - 3 } & Group B & $9.09 \pm 0.562$ & & \\
\cline { 2 - 3 } & Group C & $9.11 \pm 0.832$ & 609.144 & \multirow{3}{*}{0.0001} \\
\hline \multirow{4}{*}{ P1 } & Group A & $3.89 \pm 0.530$ & & \\
\cline { 2 - 3 } & Group B & $4.00 \pm 0.243$ & 1136.474 & \multirow{2}{*}{0.0001} \\
\cline { 2 - 3 } & Group C & $7.74 \pm 0.701$ & & \\
& Group A & $0.83 \pm 0.382$ & & \\
\cline { 2 - 3 } & Group B & $0.97 \pm 0.514$ & & \\
\cline { 2 - 3 } & Group C & $6.49 \pm 0.742$ & & \\
\hline
\end{tabular}

$\mathrm{SD}=$ standard deviation, $\mathrm{F}$-value $=\mathrm{F}$-test, $\mathrm{S}=$ significant $(\mathrm{P}<0.05), \mathrm{NS}=$ not significant $(\mathrm{P}>0.05)$ 


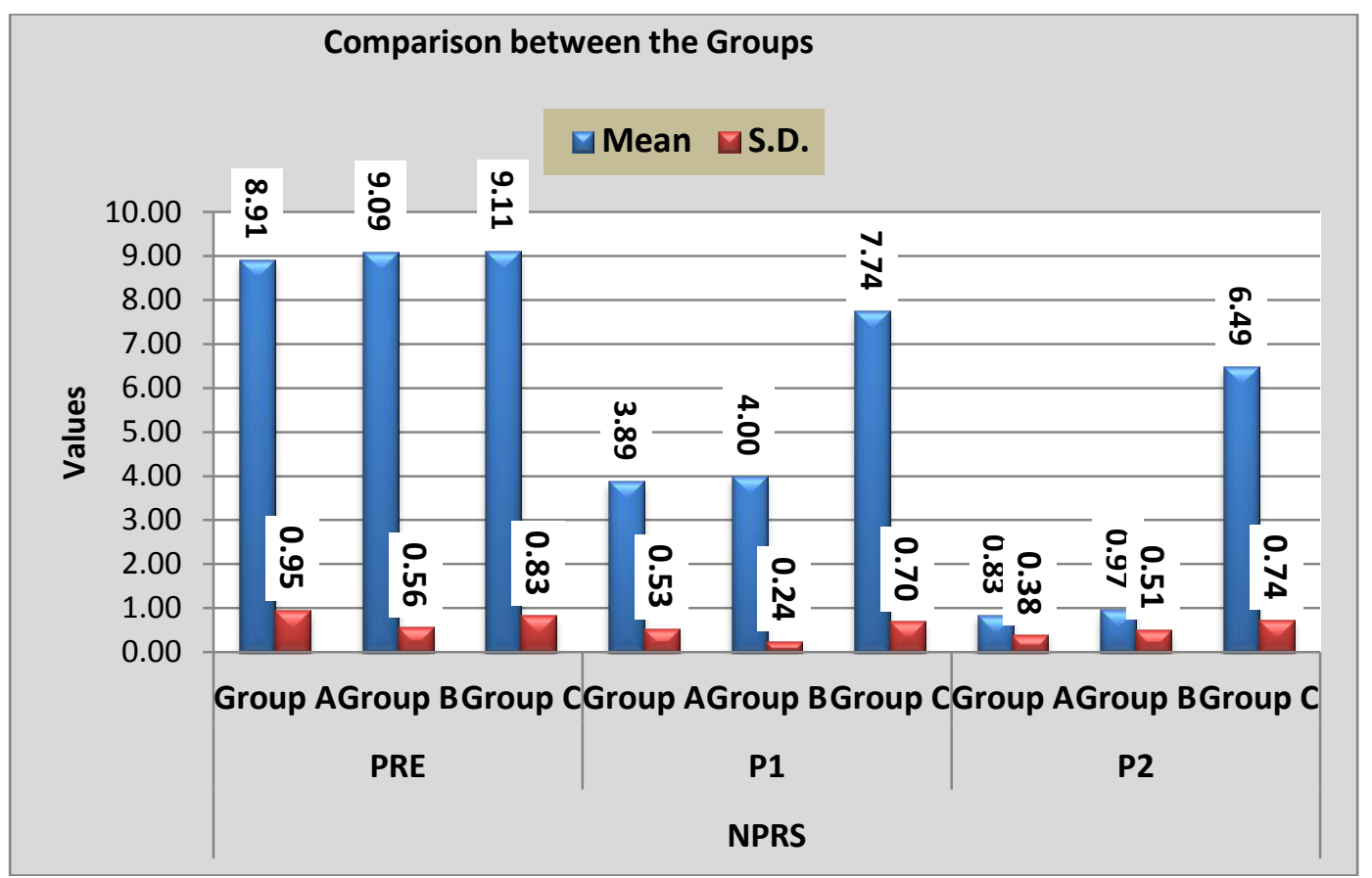

Graph4.5 showing the comparison of NPRS between the group A, group B \& group C (Mean \pm SD)

Table 5 Comparison of PDQ scores between the Group A, Group B and Group C

\begin{tabular}{|l|l|l|l|l|}
\hline PDQ & MEAN \pm SD & F-VALUE & LEVEL OF SIGNIFICANCE \\
\hline PRE TEST & Group A & $4.97 \pm 0.169$ & 0.254 & 0.777 \\
\cline { 2 - 3 } & Group B & $4.97 \pm 0.169$ & & \\
\cline { 2 - 3 } & Group C & $4.94 \pm 0.236$ & \multirow{3}{*}{30.861} & \\
\hline P1 & Group A & $3.11 \pm 0.530$ & & \\
\cline { 2 - 3 } & Group B & $3.09 \pm 0.562$ & \multirow{2}{*}{114.879} & \\
\cline { 2 - 3 } & Group C & $3.89 \pm 0.323$ & & \\
\hline P2 & Group A & $1.66 \pm 0.539$ & & \\
\cline { 2 - 3 } & Group B & $1.63 \pm 0.547$ & & \\
\cline { 2 - 3 } & Group C & $3.34 \pm 0.539$ & & \\
\hline
\end{tabular}

$\mathrm{SD}=$ standard deviation, $\mathrm{F}$-value $=$ F-test, $\mathrm{S}=$ significant $(\mathrm{P}<0.05), \mathrm{NS}=$ not significant $(\mathrm{P}>0.05)$

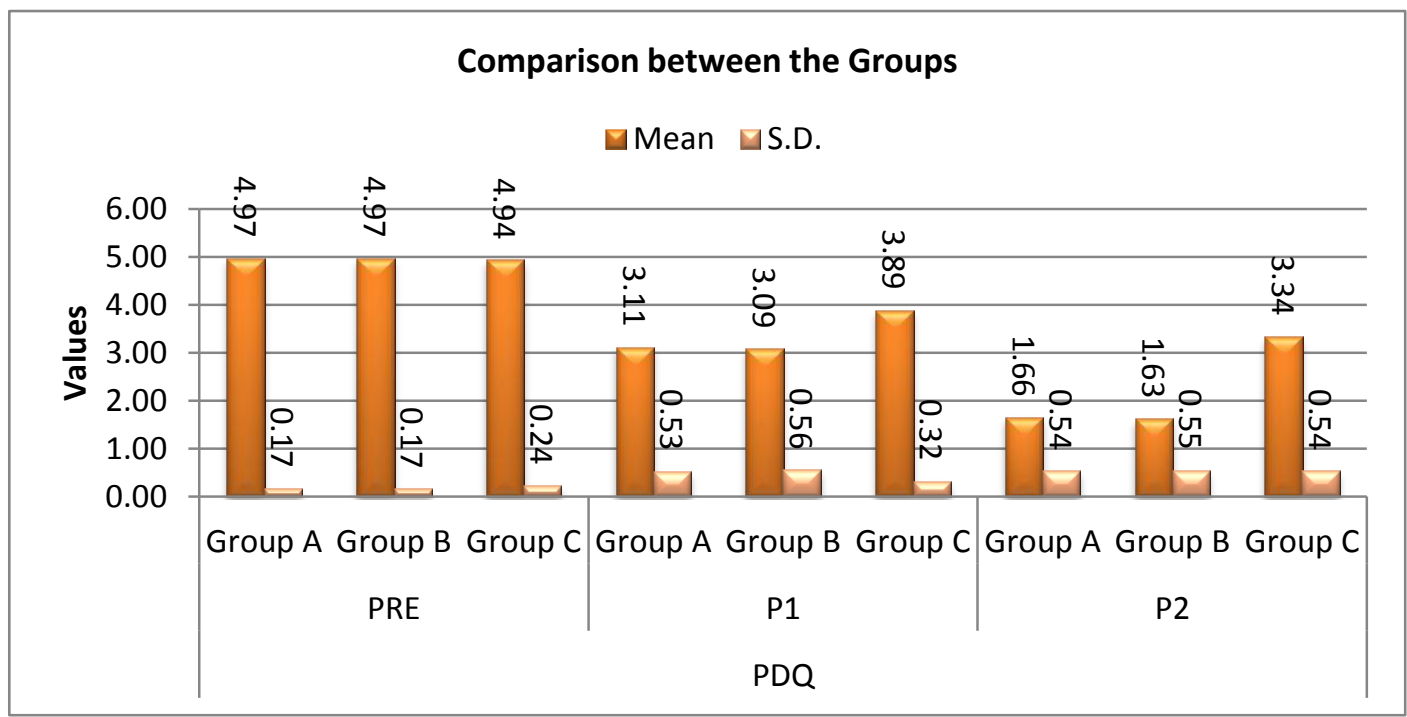

Graph4.6 showing the comparison of PDQ between the group A, group B \& group C (Mean \pm SD) 
Table 6 Comparison of Side Bridge Test between the GroupA, GroupB \& Group C

\begin{tabular}{|l|l|l|l|l|}
\hline SIDE BRIDGE TEST & MEAN \pm SD & F-VALUE & LEVEL OF SIGNIFICANCE \\
\hline \multirow{4}{*}{ PRE TEST } & Group A & $10.94 \pm 5.116$ & 0.563 & \\
\cline { 2 - 3 } & Group B & $10.63 \pm 5.515$ & & \\
\cline { 2 - 3 } & Group C & $9.71 \pm 4.396$ & & \\
\hline P1 & Group A & $34.03 \pm 5.096$ & 404.342 & 0.0001 \\
\cline { 2 - 3 } & Group B & $69.69 \pm 9.649$ & & \\
\cline { 2 - 3 } & Group C & $19.83 \pm 7.229$ & \multirow{2}{*}{0.0001} \\
\hline P2 & Group A & $56.06 \pm 6.747$ & & \\
\cline { 2 - 3 } & Group B & $104.06 \pm 12.609$ & & \\
\cline { 2 - 3 } & Group C & $30.17 \pm 9.998$ & & \\
\hline
\end{tabular}

$\mathrm{SD}=$ standard deviation, $\mathrm{F}$-value $=$ F-test, $\mathrm{S}=$ significant $(\mathrm{P}<0.05), \mathrm{NS}=$ not significant $(\mathrm{P}>0.05)$

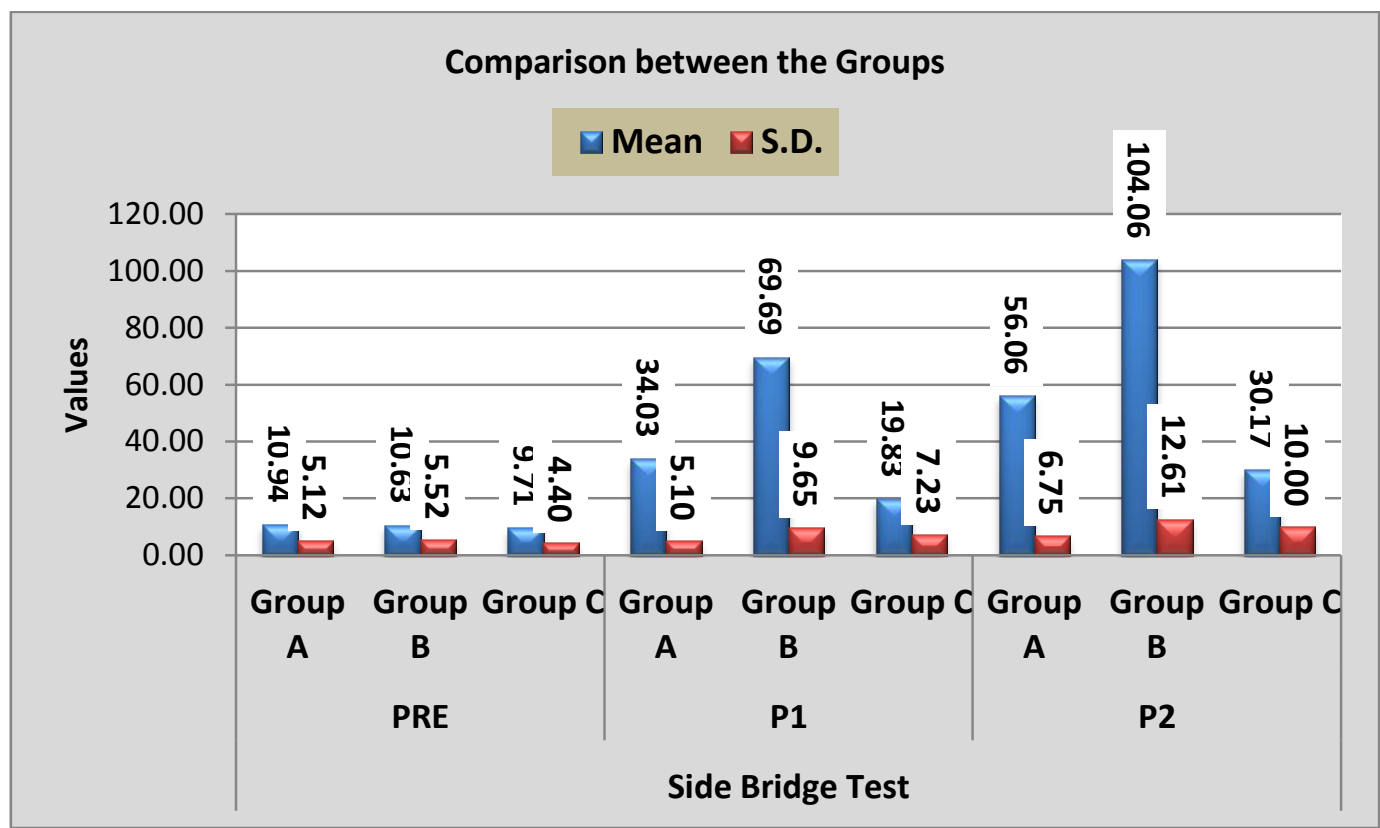

Graph4.7 Showing the comparison of Side bridge test between the group A, group B \& group C (Mean \pm SD

\section{Discussion}

The disabling nature of pain makes dysmenohreea distressing and it can become important factor in the lives of very women, especially who are self supporting. Some women are completely prostrated and confined to bed, where as others are able to remain afoot with the aid of analgesics. The present study was conducted to see which exercise protocol is more better either active stretching or core strengthening in primary dysmenorrhea, In this study almost $90 \%$ of the treated women reported a reduction in menstrual pain or the complete disappearance of pain after an average of 8 weeks of exercises (GP1 and GP2), The findings are similar to those of various authors have showed a correlation between life stress and gynaecological with premenstrual syndrome (3). Golomb et all ${ }^{[45]}$ concluded that Exercise is widely accepted as a mean of moderating stress and biochemical changes in the immune system. A mechanism by which exercise may improve the symptoms of dysmenorrhoea (reducing stress) has been articulated by Golomb et al ${ }^{[45] .}$ Menstrual pain probably stems from increased contraction of the uterine muscle, which is innervated by the sympathetic nervous system. Stress tends to enhance sympathetic activity, and may therefore increase menstrual pain by exacerbating uterine contraction. By relieving stress, exercise may decrease this sympathetic activity, thereby alleviating symptoms. In fact, exercise is known to cause the release of endorphins, substances produced by the brain that raise the pain threshold ${ }^{[2] .}$

There is significant reduction in pain intensity by NPRS in both experimental groups (Gp1\&Gp2).There is reduction of pain from 8.91 to 3.89 (4weeks) to 0.83 in Gp1,and there is reduction of pain from 9.09 to 4 ( 8 weeks) to 0.97 but where as in control group no significant results were observed. The role of exercise therapy as a tool for reducing stress and biochemical changes in the immune system was considered extensively as well. Izzo and Labriola ${ }^{[46]}$ proposed that the increase in the blood flow and metabolism of the uterus during exercise may be effective in the reduction of dysmenorrheal symptoms. In another words, improved metabolism is a factor in the reduction of symptoms. It is also suggested that increased menstrual pain by uterine muscle contraction is derived from a nervous system that is innervated by the sympathetic nerve hence; stress through hyperactivity of sympathetic nerve system via the increase contractibility of uterine 
muscles may lead to menstruation symptoms. Consequently, it might be possible to reduce dysmenorrheal symptoms by decreased sympathetic over-activity through exercise. Another hypothesis suggests that therapeutic exercise can increase the secretion of endorphins from the brain, and these materials in turn raise the pain threshold of the body.

There is significant increase in a core strength in both experimental groups which is determined by side bridge test. In Gp1 there is increase in strength from 10.94 to 34.03(4weeks)to56.06(8weeks)and In Gp2 there is increase in strength from 10.63 to 69.69 (4weeks) to 104.06 ( 8 weeks) but no significant results came in Gp3.These findings have shown that core strengthening exercises act to stabilize the lumbar spine. The menstrual cycle is an incredible stress to the female body. During the stress of menstruation, weak core musculature creates an inability for the body to handle the forces required for normal movement and function, thus leaving the female body vulnerable to the pain associated with improper biochemical function of the structures adjacent to the lumbar spine ${ }^{[15]}$. Training of the core musculature has been proven very important in both the reduction and prevention of low back pain both in athletes and the average population .A major objective of core training is to exercise the abdominal and lower back muscles in unison (Clark, p.200 $0^{[31]}$. Increasing the strength and flexibility of the core to increase trunk flexion and extension has also shown to decrease the amount of pain that chronic low back sufferers report (Donchin-abstract p.1) ) $^{[32]}$ the core muscles must function synergistically in order to stabilize the lumbar spine of an individual. Research confirms that in healthy individuals, activation of the core muscles occurs before any movement of the body or a body segment. This confirms that the core muscles are essential for optimal stabilization (Aaberg, p.45) ${ }^{[30] \text {. }}$

Plank exercises have been proven beneficial in targeting multiple core muscles the exercise works all the muscles in your torso-this includes the deeper abdominal muscle called the transverse abdominus ,the muscles of the spine and also the muscles that support the shoulder girdle(Green p.77) ${ }^{[33]}$ this study utilizes plank exercises both on a stable and unstable surface to determine which surface to determine which surface was more beneficial which surface was more beneficial in order to train these core muscles. The study on Efficacy of core stabilization training utilizing Low plank exercises on a bosu ball by Ara Apgar et all shown the results that the group who performed the low plank exercises on a stable surface (Group 2) increased their ability to perform the side bridge by 5.77 seconds where as the group performing the low plank exercises on the unstable surface only increased their ability to perform a Mc Gill side bridge by 1.34 seconds, a difference of 4.43 seconds. These results show that core stability training on an unlevel surface is less beneficial than core stability training on a stable surface, they now target and collectively coin the core as several of the muscle compartments that emanate from approximately mid torso to mid thigh (Mannie,8) ${ }^{[35]}$ As people become more sedentary, the core muscles are used less often causing them to weaken and provide less spinal support .This weakness opens the door for a possible injury, which may lead to low back pain(kuhlenberg 8$)^{[34]}$. functional movements are highly dependent on the core , and lack of core development can result in a predisposition to injury. One of the most important components of any exercise program is core strength known as the power house of the core is the foundation or centre of the functional kinetic channel similar to the foundation of a house, the core supports and stabilizes the spine during static position and movement .core stability is defined as the ability to control the position and movement, core stability is defined as the ability to control the position and motion of the trunk over the pelvis to allow optimal production, transfer and control of force and motion to the terminal segment in integrated athlete activities. In day to day terms, core stability is necessary for efficient and injury free movement patterns,(Sonnemaker,2010) ${ }^{[39] .}$

The McGill side bridge is an exercise designed to train the quatratus lumborum, transverse abdominis, and abdominal obliques as spine stabilizers. The side bridge has become the optimal technique to maximize activation of the core but minimize the spinal load. Maintaining the side bridge position ensures constant muscle activation while the brace introduces new combination of muscle recruitment to ensure stability. Muscle endurance, as opposed to strength, has shown to be protective against future back troubles. It is almost impossible for the spine to become unstable while performing a side bridge with a neutral spine. After increasing core stability, the symptoms of dysmenohrrea were improved in the experimental group (Gp1) \& (Gp2) this finding supports the previous assertation.

There is significant decrease in symptoms of primary dysmenohrea which is determined by $\mathrm{PDQ}$ (primary dysmenohrriac questionnaire).In Gp1 there is reduction of symptoms from 4.97 to 3.11 (4weeks)to 1.66.in Gp2 there is reduction of symptoms from 4.97 to 3.09(4weeks)to 1.63(8weeks) but in Gp3 the results are non significant.

\section{Conclusion}

The present result suggested that active stretching and core strengthening both can be safely used as an alternative therapy for pain relief in dysmenorrhoea and this action is not mediated through progesterone. Because we are dealing with a functional problem that is not a disease state, so can truly focus on a holistic approach. Alternative Measures like active stretching and core strengthening that lessen psychosocial stress levels should be implemented among college students in order to augment their menstrual well-being, thereby 
potentially preventing future illness from occurring. At the end, with attention to the positive effect of exercise on dysmenorrhea, as a significant problem for college students, that causes absence from college and work, we recommend regular exercise as a helpful means in this age group. On the other hand we can do exercise in every place that do not need to any cost. Further study can be done with more samples, different populations and with other menstrual disorders like secondary dysmenohrrea \& premenstrual disorder etc.

\section{References:}

[1]. Reis Concelcao,Hardy Eleen,Souse Maria, The effectiveness of connective tissue massage in the treatment of primary dysmenorrhea among young women, RECIFE[2010]vol10[2],247-256

[2]. Jerdy Shahnaz ,Hosseini Rahman,Gh Maghsound ,Effects of stretching exercises on primary dysmenorrhea, Biomedical human kinetics[2012] vol [4]127-132.

[3]. Karampour Elham,Khoshnam Ebrahim, The influence of stretch training on primary dysmenorrhea, advances in environmental biology[2012]vol6[12]3069-3071.

[4]. Chaudhari Aditi,Singh Amarjeet,Dhaliwal Lakhbir,A randomised controlled trial of exercise and hot water bottle in the management of dysmenorrhea in school girls of Chandigarh,india,Indian J physical pharmocol[2013]vol57[2]114-122.

[5]. Saadatabadi Fatehmeh, Bambaichi Esfaryani fahimeh,Effects ofsix weeks flexibility training on dysmenohrrhea, Journal of Isfahan medial school[2010] vol28,no.109

[6]. Gumus Iiknur et all Impact of home based exercise on quality of life of women with primary dysmenorrhea,SAJOG,[2012]vol $18, \mathrm{NO}$.

[7]. J Brown,S Brown ,Exercise for dysmenorrhea, the Cohrance collaboration,published by john willy\&sons Ltd,[2010],vol2.

[8]. Mahvash Noorbaksh,Eidy Alijani,Mehndi Kohandel,Zahra Mehdizadeh,Mani Mirfaiz,Shahla Hojat, The effects of physical activity on primary dysmenorrhea of female university students, world applied sciences journal[2012]vol17[10]1246-1252

[9]. Arayo luana, sliva jose ,bastos weltianne, ventura patricia pain improvement in women with primary dysmenorrhea treated with pilates ,REV D OR saoPaulo[2012]vol13[2]119-23.

[10]. Aganoff Julie, Boyle Gregory,Aerobic exercises mood states and menstrual cycle symptoms,Humanities and social sciences paper[1994]http//epublications .

[11]. Nagusha,Kodali Madhavi,Effects of yoga on Primary dysmenorrhea and stress in medical students ,IOSR journal of dental and medical sciences[2013]vol4pp69-73

[12]. $\mathrm{N}$ Shavandi,F Taghian, $\mathrm{V}$ Soltani,The effects of isometric exercise on primary dysmenorrhea,Arak medical university journal[AMUJ][2010]vol13[1] 71-77.

[13]. Zabbaspour,M Rostami,Sh.Najjar, the ffects of exercise on primary dysmenorrhea,JRes health sciences[2006]vol6,no.1pp26-31

[14]. Mannheimer Jeffrey and Whalen Eileen, The efficacy of Tranccutaneous electrical nerve stimulation in daysmenohrrea, the clinical journal of pain [1985],vol1no:2

[15]. Light Natausha,Palmer Nikki,Utrup Chris,the effects of core strengthening on dysmenorrhea,oct[2006].

[16]. Wang etal Stress and dysmenorrhea:a population based prospective study,Occupation environmental medicine[2004],vol[61]1021 1026.

[17]. Vance R,Hayes Sherrill,Speielholz Neil microwave diathermy treatment for primary dysmenorrhea,Journal of the Ameroican Physical Therapy association[1996]vol[76]1003-1008.

[18]. Daley A J,The role of exercise in the treatment of menstrual disorder,Br.J.Gen.practi,[2009]vol[59]241-242.

[19]. IzzoA,D Labeiola dysmenorrhea and sports activities in adolescenent ,clinical Exp.Obst.and gynaecology[1991]vol18,109-116

[20]. Johnson $\mathbf{J}$ level of knowledge among adolescent girls regarding effective treatment for dysmenorrhea,J.A adolescenent girls,regarding effective treatment for days,J.Adolesence .health care[1988]vol9,399-402.

[21]. Rumball J.S,Cmlebrun,prepaticipation physical examination,selected issues for the female athlete,Aim J.sport medivcine[2004]vol,14153-160.

[22]. Karampour Elham, Khoshnam Ebrahim, Poordast Tahere, The influence of stretch training on primary dysmenohrrea, Advances in Environmental Biology(2012), volume 6(12):3069-3071.

[23]. Khoshnam Ebrahim et al, [2014], the effect of 8 weeks of aerobic training on primary dysmenohrrea, European journal of experimental biology (2014),4(1):380-382.Available online at www.pelagiaresearchlibrary.com.

[24]. Editorials, the role of exercise in the treatment of menstrual disorders [April 2009] British Journal of General Practice, the department of primary care and general practice, university of Birmingham.

[25]. U Nag, VK Chakravarthy, KC Burra, effect of yoga on progesterone levels and pain relief in primary dysmenohrrea, JRRMS,(2013)Vol-3,no.2.

[26]. Nag Usha, Kodali Madhavi, Meditation and Yoga as alternative therapy for primary Dysmenohrrea, international journal of medical pharmacological sciences(2013), volume 03 (07) 39-44

[27]. Gamit Kristina S, Sheth Megha S, Vyas Neeta J, the effect of stretching exercise on primary dysmenohrrea in adult girl's International journal of Medical Science and Public Health [2014], volume3, issue 5.

[28]. David Anderson et al, core strength testing: Data for three clinical tests, st.catherine university SOPHIA [2013] Doctor of physical therapy research papers page number21,web:http//Sophia.stkate.edu/dpt-papers.

[29]. Taghian Shavandi N F, V Soltani, the effect of isometric exercise on primary dysmenohrrea , arak medical university journal(AMUJ)(2010);13(1):71-77.

[30]. Sh Shahrjerdi. Hoseini Sheikh the effect of 8 weeks stretching exercise on primary dysmenohrrea in 15-17 aged high school student girls in Arak, (2010)volume(11),no.4.

[31]. Aaberg, Everett.Muscle mechanics .Champaign, IL:Human Kinetics,2006 .Print Clark,A Michael . Optimum performance Training for the Health and Fitness Professional: Course Manual. Calabasas, CA: National Academy of sports medicine,2004. http://books.google.com/books?id=-qW8oV-

$\underline{\text { SXo4C\&pg=PA200\&dq=core+training+to+reduce+back+pain\&hl=en\&ei=SKaUTp9Mf10gHP05WwBw\&sa=X\&oi=book_result\& }}$ $\mathrm{ct}=$ result $\&$ resnum $=6 \& v e d=0 \mathrm{CGQQ6AEwB}$

[32]. Donchin, Milka MD, MPH, Woolf, Ofra MPH, Kaplan, Leon MD, Floman , and Yizhar MD. "Secondary prevention of Low Back Pain: A Clinical Tria."Spine 15.12(1990).web<http://journals.lww.com/spinejournal/Abstract/1990/12000/Secondry prevention of low back pain A -Clinical.15.aspx>.

[33]. Green, Yolande. Weight-bearing Workouts for Women: exercises for Sculpting, Strengthening and toning.Berkely,CA:Ulysses,2004http://books.google.com/books?id=cKTLEALFBQAC\&pg=PA77\&dq=plank+exercises\&hl=en\&e 
$\mathrm{i}=\mathrm{X} 6 \mathrm{SUTuKYIsODsgLLoPXuAQ \& sa}=\mathrm{X} \&$ oi $=$ bookresult\&ct=result

\&resnum $=6 \& v e d=0 C E c Q 6 A E w B Q \# v=$ onepage $\& q=$ plank $\% 20$ exercises $\& \mathrm{f}=$ false. Web

[34]. Kuhlenberg.Eric."Core stability."Hughston health alert 18.1(2006):7-8 webs.

[35]. Mannie, Ken, and Mike Vorkapich. "Sliding into a strong core "Coach and athletic Director 76.4(2006):8-10.Print

[36]. GillMc, MStuart, and Karpowicz Amy.”Exercises for spine Stabilization”:Motion/Motor Patterns, Stability Progressions ,and Clinical Techniques .Arch Physical Medical Rehabilitation 90(2009),118-26.web

[37]. Norris, M Christopher ."Chapter 3".Back Stability: Integrating Science and Therapy.2 ${ }^{\text {nd }}$ ed. Champaign, IL: Human Kinetics, 2008.51-59.Print.

[38]. Park house BSc, ASCC, L Kelly and Ball Nick PhD, ASCC, CSCS."Influence of Dynamic versus Static Core Exercises on Performance in field based Fitness Tests."Journal of bodywork and Movement Therapies 15.4(2011):517-24.

[39]. Sonnemaker, Bill, and Ryan Halvorson. Core Stability for Enhanced Daily Function. IDEA Fitness Journal 7.1(2010):25-58.Print

[40]. GillMc S M childs A, C Liebenson Endurance times for low back stabilization exercises :clinical targets for testing and training from a normal database ,PMID, Pubmed.

[41]. Doyamaz $\mathrm{F}$, analyzing the effects of physical characteristics on trunk muscles endurance bin healthy Turkish subjects, Eur $\mathbf{J}$ Phsiol.(2006) 96 (3)241-8.

[42]. KellRT, Bhambhani Y relationship between erector spinae static endurance and muscle oxygenation-blood volume changes in healthy and low back pain(2005).PMID

[43]. Liebenson Craig, DC documentation of physical capacity: it is purpose in rehabilitation, Pubmed.

[44]. Apgar Ara , Darke Kartie , Maberry Shannon , O Lindsay Nan ,the efficacy of core stabilization training utilizing low plank exercises on a bosu ball, 10/13/11

[45]. 1.M Golomb,Solidium A.A.,waren,primary dysmeohrehea and physical activity,(1998),Medical science sports exercise,30:508-511

[46]. A.Izzo,Labriola D,dysmeonohrea and sports activities in adolescents(1991) clinical experimental obstet gynecol.18:109-116. 